\title{
SER ALÉM DOS MUROS: FENOMENOLOGIA DA LIBERDADE PARA IDOSOS INSTITUCIONALIZADOS
}

\author{
Being beyond walls: a phenomenology of freedom for institutionalized elderly \\ Más allá de las paredes: fenomenología de la libertad para ancianos institucionalizados
}

Diogo ARnALDO CORRÊA

Carla de Santana Oliveira Marlise Aparecida Bassani

\begin{abstract}
Resumo: O estudo objetivou compreender os significados da liberdade para nove idosos que foram entrevistados individualmente numa Instituição de Longa Permanência para Idosos localizada na região do Alto Tietê. Às suas narrativas foi procedida análise qualitativa considerando a narrativa como uma técnica em pesquisa fenomenológica. Na análise, os significados da liberdade para os idosos entrevistados se desvelaram relacionados à sua abertura e suas experiências para além das restrições institucionais e de seu momento de vida articulados nos seus modos de ser-no-mundo e ser-com-os-outros. O estudo revelou que é possível aos idosos serem livres ante as restrições que enfrentam, o que os destina às suas possibilidades de existir numa realidade transformadora de sua história pessoal para além de quaisquer fronteiras.
\end{abstract}

Palavras-chave: Envelhecimento; Institucionalização; Liberdade.

\begin{abstract}
The study aims to understand the meanings of freedom for nine elderly individuals who were interviewed individually in a home for old people located in the Alto Tietê. Its narratives were made by qualitative analysis, considering the narrative as a technique in phenomenological research. In the analysis, the meanings of freedom for the elderly people respondents proved to be related to your opening and your experiences in addition to the institutional constraints and your moment of life hinged on their ways of being-in-world and being-with-the-others. The study showed that it is possible for the elderly are free before the restrictions they face, what is intended by their ability to exist in processing of your reality personal history beyond any borders.
\end{abstract}

Keywords: Aging; Institutionalization; Freedom.

Resumen: El estudio buscó comprender los significados de la libertad para nueve ancianos que han sido entrevistados individualmente en un asilo de ancianos ubicado en Alto Tietê. Sus narrativas se analizaron cualitativamente considerando la narrativa una técnica en la investigación fenomenológica. En el análisis, los significados de libertad para los ancianos entrevistados se revelaron relacionados con su apertura y experiencias más allá de las limitaciones institucionales y momento de vida articulado en sus modos de ser en o mundo y ser con los otros. El estudio reveló que la libertad es posible para los ancianos incluso frente las restricciones que enfrentan, que señala sus posibilidades de existir en una realidad transformadora de su biografía más allá de cualquier frontera.

Palabras-clave: Envejecimiento; Institucionalización; Libertad.

\section{Introdução}

Os diversos significados designados ao envelhecer desafiam a compreensão sobre os modos de ser-no-mundo de uma pessoa idosa. Guimarães e Carneiro (2012) e Silva et al., (2016) destacam, por exemplo, o envelhecer como sinônimo de declínio enfatizando a perda de várias das funções fisiopsicológicas. Minayo e Coimbra Júnior (2002), por sua vez, referem a ideia de "peso social" em relação à pessoa idosa assinalando que o direito da aposentadoria é um dos aspectos reforçador dessa noção combinado aos imperativos do sentimento de rebaixamento da produtividade e a perda de laços afetivos.

As indagações acerca do momento do desfecho da vida e a proximidade da morte (Teixeira \& Neri, 2008) é outro aspecto que assinala a heterogenia sobre o envelhecer. E Alves-Silva, Scorsolini-Comin e Santos (2013) ainda destacam a representação do envelhecimento como adversidade e empecilho no contexto das interrelações familiares levantando diversos conflitos que podem encaminhar a inserção do idoso em uma Instituição de Longa Permanência para Idosos por vontade da pessoa idosa ou por determinação dos familiares.

As Instituições de Longa Permanência para Idosos delimitam-se como espaços que oferecem assistência às pessoas idosas procurando garantir seu bem-estar físico, psicológico e social em consonância ao Estatuto do Idoso e demais políticas voltadas a idosos. Nelas, o poder disciplinar é característico, regido por normas que privam a pessoa idosa de se expressar de modo singular e livre (Alves-Silva, Scorsolini-Comin \& Santos, 2013). Institucionalizada, mesmo recebendo cuidado para suprir suas necessidades imediatas, a pessoa idosa confronta-se com novos desafios como o relacionar-se socialmente com pessoas que estão no mesmo momento de vida que ela - e, às vezes, somente com elas -; o suportar a ausência da família e dos amigos; 
o adaptar-se a uma rotina e a regulamentos e normas próprias da instituição que visam o bem-estar coletivo e a procura e participação individual ou coletiva em atividades que preencham as lacunas do tempo vivido na instituição (Pavan, Meneghel \& Junges, 2008; Alves-Silva, Scorsolini-Comin \& Santos, 2013).

Freitas, Queiroz \& Sousa (2010) destacam que, em situações de institucionalização, adoecimentos tornam-se percalços frequentes e limitantes para os idosos. Por isso, a independência para os cuidados consigo passa a ser importante critério de bem-estar.

A questão que se apresenta nesse contexto, para a qual essa pesquisa objetiva esboçar respostas é: como a pessoa idosa pode experienciar a liberdade em uma instituição de longa permanência para idosos? Compreender os significados da liberdade para o ser humano requer o debruçamento reflexivo sobre as experiências dadas na facticidade em-o-mundo. Afinal, toda reflexão é um exercício do entendimento daquilo que acontece na vida e sobre as coisas do mundo, retirando o fenômeno de seu velamento e o lançando à luz, sendo revelados novos aspectos (Critelli, 2013).

Para Heidegger (1989/1999), a liberdade faz referência à abertura própria do Dasein. Trata-se de um entregar-se do Dasein ele mesmo à sua abertura, um conferir-se a si mesmo. Dasein é o modo como indica o ser da existência. Nesse desvelar-se, o "deixar-se, isto é, a liberdade, é, em si mesmo, exposição ao ente, isto é, ek-sistente" (Heidegger, 1989/1999, p. 161). Na atitude de ser-com-os-outros, a existência é assinalada pela liberdade num horizonte de possibilidades. Desse modo, o ser humano é livre para escolher por aquilo que está no mundo e para ser ele mesmo ou não. Ser livre implica ser inacabado, ser incompleto. Assim, a existência busca dar sentido, encaminha-se na procura das razões sobre seu existir e permanece numa constante inconclusão. O tempo todo há algo pendente que, por ele, pode ser compreendido e interpretado (Heidegger, 1927/2012).

A liberdade para ir e vir está articulada com a espacialidade existencial. Conforme Rée (2000), o espaço vivido é definido pelas várias atividades cotidianas e vivenciado em termos de proximidade e distância. E Almeida Prado, Caldas e Queiroz (2012) destacam que a existência não se movimenta no mundo de acordo com o que entende objetivamente como espaço, mas segundo sua intencionalidade que o situa no mundo. Assim, a vivência espacial do idoso torna-se uma importante questão na análise do ser-no-mundo no cenário do envelhecer.

\section{O Percurso do Estudo}

O estudo foi marcado por três momentos: (1) a realização de entrevistas com nove idosos de uma Instituição de Longa Permanência para Idosos; (2) a transcrição de seus discursos e (3) a realização de análise qualitativa das alocuções considerando a narrativa como uma técnica em pesquisa fenome- nológica conforme defendido por Dutra (2002).

A análise qualitativa em pesquisas fenomenológicas, de acordo com Moreira (2002), compreende três aspectos fundamentais: a) a construção ativa do conhecimento a partir da análise das ideias expressadas na linguagem; b) uma observação dinamizada a partir do revelado que conserve o que os entrevistados apresentaram e c) a descrição e interpretação do modo como os participantes relacionaram suas experiências (o que foi vivenciado), os significados (o que acredita-se ter sido experienciado), a linguagem (a designação acerca do vivido) e os comportamentos (o que a pessoa realizou durante o vivido).

E a narrativa como técnica em estudos situados na esteira fenomenológica, de acordo com Dutra (2002), inspira-se nas ideias de Benjamin (1994) e sustenta-se na noção de que o retorno às experiências dos entrevistados implica o reconhecimento da abertura e da relação pelas quais estamos inferidos no mundo. Em se tratando dos procedimentos metodológicos em razão de tal noção, Dutra (2002) defende que os discursos dos participantes "[...] devem ser gravados, transcritos e literalizados. Posteriormente, devem ser submetidos à apreciação dos entrevistados, para que os mesmos possam conferir a sua fidelidade à narrativa feita. A seguir, os depoimentos são comentados e interpretados, a partir dos significados que se revelam na experiência narrada e como produto das reflexões feitas pelo pesquisador na sua trajetória de vida pessoal e profissional, ancoradas numa ótica existencial da condição humana.” (p. 377).

Nesse sentido, os nove idosos participantes do estudo foram entrevistados individualmente numa ILPI localizada na região do Alto Tietê sendo utilizadas as seguintes perguntas: "o que é liberdade para o(a) senhor(a)?” e "o(a) senhor(a) se sente livre residindo aqui?". Dos nove participantes, cinco eram do gênero feminino e quatro do gênero masculino. As entrevistas foram realizadas de modo que os entrevistados pudessem discorrer livremente a respeito do tema e, via diálogo com o entrevistador, aprofundá-lo.

Na transcrição dos discursos e na análise das informações consideraram-se os cuidados éticos conforme o Termo de Consentimento Livre e Esclarecido utilizado no protocolo do estudo fazendo viger a preservação da identidade dos participantes (para assinalar nos excertos das narrativas a identificação dos participantes foram adotadas as iniciais de seus nomes).

Após a transcrição das narrativas, conferidas em sua integralidade pelos participantes, procedeu-se a análise em busca do significado do mundo da experiência dos participantes entendendo-se que a procura dos significados do vivido numa narrativa corrobora a confiança do "[...] mundo para as coisas, abrigando ao mesmo tempo as coisas no brilho do mundo. $\mathrm{O}$ mundo concede às coisas sua essência. As coisas são gesto de mundo. O mundo concede as coisas" (Heidegger, 1959/2003, p. 18).

No percurso metodológico do estudo, portanto, concentrou-se o interesse nos significados atribuídos pelos participantes às experiências em seu 
mundo vivido, conforme expõe (Moreira, 2002) considerando-se a participação dos pesquisadores em todas as suas dimensões existenciais no momento da narrativa dos participantes acerca do seu vivido. Afinal, conforme Dutra (2002) "assumir uma estratégia qualitativa de pesquisa fenomenológica, como a narrativa, significa, antes de tudo, adotar como horizonte teórico e filosófico a existência, compreendida na experiência vivida. [...] A narrativa, portanto, ao considerar essa dimensão do mundo vivido, nos sinaliza com a possibilidade de nos aproximarmos do outro, sem que se perca a principal característica que o distingue no mundo, que é a existência” (p. 377).

\section{Os Significados da Liberdade Desvelados pelos Idosos na ILPI}

Revelaram-se nas narrativas dos idosos as alcunhas do seu ser-livre sedimentadas em sua cotidianidade na Instituição de Longa Permanência para Idosos. Inicialmente, seu ser-livre se revelou nas restrições do poder deliberar sobre algo, tomar decisões e fazer escolhas para si e por si no cotidiano vivido na Instituição de Longa Permanência para Idosos.

“[...] Aqui a gente não se sente livre [...] fazer coisas de artesanato a gente pode fazer, mas outras coisas não. A gente não tem liberdade para fazer o que a gente quer” (BC).

"Eu me sentia melhor para fazer as coisas dentro da minha casa, não é? Porque, às vezes, você quer fazer alguma coisa aqui e você não pode fazer" (MJ).

As narrativas manifestam essa noção e referem que se adaptar às novas normas é um dos desafios enfrentados pelos idosos que partem de um ambiente familiar para um novo lugar onde são priorizadas as necessidades coletivas, conforme discutido por Pavan, Meneghel \& Junges, (2008). Visto que as instituições de longa permanência são marcadas por uma rotina diária regida por horários determinados tal como regras rígidas, o modo de ser singular e as escolhas individuais podem ter um caráter secundário quando comparadas às coletivas (Alves-Silva, Scorsolini-Comin \& Santos, 2013). Mas, a possibilidade de escolher, mesmo em regime de institucionalização, não é exonerada pelos idosos.

"Eu posso arrumar meu cabelo, posso tingir o cabelo, eu posso deitar a hora que eu quiser. Eu posso fazer tudo o que eu quiser. A única coisa que eu não gosto é tomar sopa à tarde ou senão eu faço assim: como o lanche das três horas ou tomo a sopa” (NL).

"Você tem um pouco de liberdade. Você pode andar o horário que você quiser” (LA).

Tais discursos mostram as possibilidades de escolha pelos idosos em situações simples do cotidiano nas quais mais de uma opção é dada para o seu vir-a-ser. Escolher entre tomar sopa e comer o lanche da tarde ou o horário para caminhar constituem formas de expressão da liberdade mesmo em instituição. Nestas situações, ainda que subsista um conjunto de regras e normas a serem seguidas, a autodeterminação referida em algumas escolhas individuais pode ser preservada. O ser-livre para os idosos institucionalizados expressa-se também no sentido de um modo de existir que transcende a ditadura do impessoal surgido na convivência com o outro.

“Às vezes você tem limites e tem que respeitá-los, ou seja, pelos terceiros ou de qualquer forma você tem que respeitar, não é? ” (LA).

Respeitar as regras pelos terceiros faz alusão ao ser-com-o-outro. É acolher as restrições vigentes na Instituição de Longa Permanência para Idosos não só por si, mas também pelo outro. Conforme coloca Freitas (2011), o respeito pela liberdade do outro representa a origem do espaço da própria liberdade. Assim, o exercício da autodeterminação dos idosos na Instituição de Longa Permanência para Idosos se mostra no seu acolhimento às regras e limites que ali estão tramadas no viver em-o-mundo-com-os-outros. As exigências na instituição acabam sendo condições para algo. E, recolhendo os limites que inferem sobre seu ser naquela realidade, realizam o seu ser-livre em direção a si mesmo e ao outro em um mundo que impõe suas próprias reservas. Ou seja, é-se livre sendo com os outros, conforme a fala de uma entrevistada:

"Aqui é livre, viu? Só quando eu estou doente que eu preciso de ajuda, mas quando estou saudável eu faço tudo o que desejo sozinha." (NL)

No envelhecer, os idosos são desafiados por experiências de adoecimento decorridas dos percalços próprios desse momento da vida. Por isso, à medida que a pessoa envelhece, seu bem-estar passa a ser determinado, em muitos casos, pela capacidade de manter-se em sua independência (Freitas, Queiroz \& Sousa, 2010). Todavia, como uma restrição temporária das possibilidades que não retira do existir o poder ser livre, o estar doente é compreendido como um convite para ainda escolher, apesar de tudo: ser-com-o-outro referido num pedido de ajuda que assinala a solicitude.

“[...] Aqui você tem uma liberdade diferente. Você tem a liberdade aqui dentro, não é? Não tem a sua liberdade lá de fora. [...] É isso que me foi tirado, não é? Essa liberdade lá de fora. E talvez eu já não esteja na idade de gozar essa liberdade. Principalmente pela idade, porque você acha que pode fazer, mas na realidade não pode. Você fica restrito. Então a solução, o que é? É você com a sua liberdade aqui dentro ir tentando conviver" (LA). 
A narrativa de LA expressa a compreensão das possibilidades que lhe estão à mão a partir da liberdade que é experienciada na instituição. Esse posicionamento também é encontrado na fala de JX, que afirma:

“[...] estou aqui há quatro anos e pouco. Então eu fico meio enjoado [...] Aí do outro lado eu penso também que lá fora não está fácil, não é? [...] Aqui eu me acho mais livre".

As nuances próprias do envelhecer, expressadas nas dimensões psicológica, biológica e social do idoso, aludem a uma tensão entre aquilo que o idoso gostaria de fazer (sua vontade) e aquilo que ele pode fazer (sua realidade). Tal tensão pode ser interpretada equivocadamente como um tipo de aprisionamento. No entanto, conforme defende Freitas (2011), mesmo que se revele encolhida, a condição humana de liberdade permanece presente à medida que a existência se posiciona diante das reservas que se lhe apresentam no mundo.

A temporalidade é outro elemento que se mostra em relação ao ser-livre dos idosos em uma Instituição de Longa Permanência para Idosos. NL menciona o lanche das três horas da tarde. LA refere que pode caminhar na ILPI no horário que quiser e que talvez já não esteja no tempo de gozar da liberdade. JX alude que já está há mais de quatro anos na Instituição de Longa Permanência para Idosos. Nestas narrativas, a cronologia abarca uma totalidade, engloba o envelhecer como um processo complexo e multifatorial que permeia a existência com memórias dadas num hoje e para um devir.

Para o cuidado da liberdade, as Instituições de Longa Permanência para Idosos podem propiciar direções relevantes para os contornos do sentido do ser-livre do idoso. A esse respeito Piexak, Freitas, Backes, Moreschi, Ferreira \& Souza (2012) retratam o acolhimento humanizado das pessoas idosas fornecendo-lhes alimentação, cuidados com higiene, moradia, segurança e saúde, além de proporcionar atividades recreativas, esportivas, manuais e sociais possibilitando um envelhecer digno e, o quanto possível, independente. Pois, como informa uma entrevistada,

“a liberdade é não viver preso. É muito ruim viver preso. Viver na liberdade é bom, mas, agora, ficar preso num lugar só... Preso, preso, preso a gente desanima” (LI).

O viver livre é não viver preso. Na relação entre liberdade e prisão, é revelada a significação de espaço e limites físicos como determinantes para as possibilidades de liberdade que aqui aparecem a priori atadas e sem condução para espaços afora. Essa significação de espaço ou espacialidade é uma localização humana finita que compreende lugares apropriados simbolicamente e não somente um espaço geométrico. Conforme Rée (2000), esses espaços são definidos pelas várias atividades e amenidades e daquilo que mais próximo se encontra ao poder habitar. Corrobora esta afirmação a análise da espacialidade de Almeida Prado, Caldas e Queiroz (2012), para quem a existência não se movimenta no mundo de acordo com o que entende objetivamente como espaço, mas segundo sua intencionalidade, que o situa no mundo.

Dessa forma, a intencionalidade dos idosos relacionada à instituição os situa num lugar onde os muros delimitam seu espaço acessível, restringindo suas escolhas e ações àquelas possíveis naquela área. E, assim, habitam em seu ser-livre nesse espaço geográfico que pode ser transposto, ou não.

LI assinala a impossibilidade dessa transposição:

“para mim, ficar aqui é uma prisão” (LI).

Nesta perspectiva, entende-se que a liberdade em "não viver preso" configura-se na relação entre o limite físico estabelecido pela instituição e a viabilidade de ultrapassá-lo abrindo-se as portas que restringem. LT, por sua vez, amplia a noção do "não viver preso" relatando que, em sua chegada na Instituição de Longa Permanência para Idosos, percebeu que:

"eles prendiam muito as pessoas que estavam aqui. As pessoas que vinham para aqui eram presas; assim, não podiam nem vir conversar com ninguém. Não podiam. A gente não podia ter liberdade nenhuma, não é?" (LT)

É no projetar-se que o ser humano pode assumir ou não a sua existência. Em tal projetar-se, circunscreve-se a possibilidade de ser ou não si mesmo numa liberdade antecipatória, um desígnio por si mesmo para além de qualquer aspecto restritivo, desígnio que revela a existência assinalada pela liberdade num horizonte de possibilidades em que pode escolher ser ele mesmo autenticamente, ou não (Corrêa \& Brojato, 2016).

As possibilidades de o idoso assumir ou não seu ser livre numa Instituição de Longa Permanência para Idosos referem-se ao exercício de sua autodeterminação para além das paredes da instituição. Mesmo havendo um espaço restritivo que pode promover o sentimento de estar-preso, a pessoa também pode se colocar a caminho da liberdade, do voo livre em sua abertura plena (Freitas, 2011).

Nesse sentido, a liberdade é uma potencialidade do ser livre do idoso enquanto existência, um ente privilegiado que se projeta transcendendo a espacialidade num tempo. Em seu ser-livre, o idoso, no contexto de uma Instituição de Longa Permanência para Idosos está para além dos muros que o contornam afinando a realidade que o circunda àquilo que lhe é próprio. Pois, conforme defendem Sá e Barreto (2011), afinação é o modo como o ser humano, enquanto abertura de sentido, sintoniza aquilo que lhe vem em encontro no mundo se relacionando de diferentes modos com os entes que a ele se apresentam.

No lançar-se para o ser-livre que supera os muros da instituição, os idosos revelaram a possibili- 
dade do entregar-se a atividades que proporcionam satisfação e realização e que ampliam seus modos de existir registrando tal afinação.

“[...] liberdade aqui é poder pedalar na bicicleta, conversar com os amigos quando vem aqui, que eu adoro falar, viu? [...] Brincar com a Priscila, com a Gisele [suas bonecas]. Fazer vestidinho para elas. Essa é a minha liberdade" (NL).

NL refere o significado da liberdade nas possibilidades de ser no presente que ocupam seu cotidiano e a partir de escolhas que a aproximam da autenticidade. Assim, a ocupação é o modo mais imediato de cuidado por preencher os dias dos seres humanos (Fernandes, 2011).

Existir é empenhar-se no mundo, se interessar pelas coisas. Para tanto, há necessidade de empenho contínuo para atualizar o que está à mão. E, assim, configurar a autenticidade, a possibilidade para a existência ser o que é em liberdade frente a tudo que se lhe apresenta no mundo. Liberdade é...

"ser livre com a sociedade, com a diretoria, com a autoridade e não aqui apenas, mas no mundo inteiro. Ser livre [...] com a nossa humanidade" (JG).

"quando saio lá para fora [no quintal da instituição] eu vou conversar com uma colega e eu me sinto bem [...] Eu fico sentada lá fora bastante tempo".

O "lá fora" é mundo no qual a palavra - "eu vou conversar" - enleva o vir-a-ser mais próprio na sua abertura para as possibilidades existenciais do ser-livre circunscrito numa temporalidade - "eu fico sentada lá fora bastante tempo”.

Assim, a existência, em sua abertura para realizar suas distintas possibilidades de ação, pode escolher e agir em benefício da sua autenticidade em diferentes contextos, inclusive em institucionalização, corroborando o entendimento expresso por Freitas (2011). O idoso, nesse sentido, pode dirigir-se para além dos muros que parecem empecilhos para seu vir-a-ser, porém, na verdade, são condições únicas que o impelem a contornar o seu escolher, falar, agir, seu superar-se e, assim, viver e existir.

\section{Considerações finais}

Nesse estudo, a compreensão dos significados da liberdade para os idosos na Instituição de Longa Permanência para Idosos se mostra embrionária numa paisagem que trata de uma fenomenologia que vem convocando, florescendo e frutificando "devido aos esforços em recuperar suas raízes e seu solo fertilizador, através de reflexões profundas e pesquisas cada vez mais intensas, o que, certamente, anuncia uma nova história a ser contada daqui em diante” (Holanda, 2016, p. 392).

O aumento da população idosa nas próximas décadas e as inerências da relevância do cuidado em cenários institucionais que visam o bem-estar das pessoas conclamam, portanto, que demais estudos tematizem e ampliem tais questões que atravessam a contemporaneidade alargando o horizonte dos sentidos do ser-livre no envelhecer e em qualquer outro momento da vida, sentidos que conjugam o passado aos certames no presente e às preocupações e repouso no futuro.

Os idosos na Instituição de Longa Permanência para Idosos vivem um constante movimento de fundação da própria história, presentificado por restrições dadas pelo envelhecimento e/ou pelo cerceamento dos muros num contexto geográfico, mas que não o privam em seu ser. Desse modo, sua liberdade é cadenciada por peculiaridades diversas como restrições dadas na instituição e em seu momento de vida e a adaptabilidade necessária ante as relações com o outro e as constantes mudanças que enfrenta. No entanto, é possível aos idosos serem livres para além de tais peculiaridades e dos muros que circundam a instituição que os abriga, pois, em sua posição ontológica fundamental, estão lançados à clareira de seu poder-ser num tempo e espaço que acendem - trazem à luz - sua realidade existencial.

A existência se dá no mundo em que habitamos. Portanto, numa Instituição de Longa Permanência para Idosos, os idosos não têm reduzidas as possibilidades de se lançarem no seu vir-a-ser numa realidade que convoca escolhas e ações com os outros e consigo gerando e transformando, no devir, a própria biografia. Afinal, como "capacidade ontológica, a liberdade pertence à essência do próprio ser. O homem é livre para se tornar algo diferente do que é; é livre sobre sua facticidade" (Corrêa \& Rodrigues, 2013, p. 40).

\section{Referências}

Almeida Prado, R. A., Caldas, M. T. \& Queiroz, E. F. (2012). O corpo em uma perspectiva fenomenológico-existencial: aproximações entre Heidegger e Merleau-Ponty. Psicologia: Ciência e Profissão, 32(4), 776-791. <https://doi.org/10.1590/S1414-98932012000400002>

Alves-Silva, J. D., Scorsolini-Comin, F., \& Santos, M. A. (2013). Idosos em instituições de longa permanência: desenvolvimento, condições de vida e saúde. Psicologia: Reflexão Crítica, 26 (4), 820-830. <https://doi. org/10.1590/S0102-79722013000400023>

Benjamin, W. (1994). Obras escolhidas. Magia e técnica, arte e política (7a ed.). São Paulo: Brasiliense.

Critelli, D. M. (2013). História pessoal e sentido de vida: historiobiografia. São Paulo: EDUC: FAPESP.

Corrêa, D. A. \& Rodrigues, C. M. D. (2013). Finitude e Sentido da Vida: do torpor à tarefa. Logos e Existência, 2(1), 37-46. Recuperado em janeiro 03, 2017, de <http://periodicos.ufpb.br/ojs/index.php/le/article/ view/15915/10038> 
Corrêa, D. A. \& Brojato, H. C. (2016). Experiência religiosa e saúde: uma perspectiva fenomenológica. Revista Científica UMC, 1(1), 6-16. Recuperado em janeiro 03, 2017, de <http://seer.umc.br/index.php/revistaumc/ article/view/27/58>

Dutra, E. (2002). A narrativa como uma técnica de pesquisa fenomenológica. Estudos de Psicologia, $7(2), \quad 371-378 . \quad \leq$ http://dx.doi.org/10.1590/S1413294X2002000200018>

Fernandes, M. A. (2011). O cuidado como amor em Heidegger. Revista da Abordagem Gestáltica, 17(2), 158-171.

Fernandes, M. G. M., \& Garcia, L. G. (2010). O sentido da velhice para homens e mulheres idosos. Saúde e Sociedade, 19(4), 771-783. <https://doi.org/10.1590/S0104$\underline{12902010000400005>}$

Freitas, D. P. (2011). Daseinsanalyse e liberdade. Revista $A B D, 15(1), 56-83$.

Freitas, M. C., Queiroz, T. A., \& Sousa, J. A. V. (2010). O significado da velhice e da experiência de envelhecer para os idosos. Revista da Escola de Enfermagem da USP, 44(2), 407-412. <https://doi.org/10.1590/S0080$\underline{62342010000200024>}$

Guimarães, I.; Carneiro, M. H. S. (2012). Envelhecimento e Finitude: qual a representação da morte? Estud. interdiscipl. envelhec., 17 (1), 7-18.

Heidegger, M. (1999). Sobre a essência da verdade. In.: Martin Heidegger: conferências e escritos filosóficos. São Paulo: Nova Cultural, pp. 149-170. (Obra originalmente publicada em 1989)

Heidegger, M. (2003). A caminho da linguagem. Petrópolis, RJ: Vozes; Bragança Paulista, SP: Editora Universitária São Francisco. (Obra originalmente publicada em 1959)

Heidegger, M. (2012). Ser e Tempo. Campinas, SP: Editora da UNICAMP; Petrópolis, RJ: Vozes. (Obra originalmente publicada em 1927)

Holanda, A. F. (2016). Fenomenologia e Psicologia no Brasil: aspectos históricos. Estudos de Psicologia (Campinas), 33(3), 383-394. <https://doi.org/10.1590/1982$\underline{02752016000300002>}$

Minayo, M. C. S.; Coimbra Junior, C. E. A. (2002). Introdução. Entre a Liberdade e a Dependência: reflexões sobre o fenômeno social do envelhecimento. In. M. C. S. Minayo; C. E. A. Coimbra Junior (Orgs.), Antropologia, Saúde e Envelhecimento (pp. 11-24). Rio de Janeiro: Fiocruz.

Moreira, D. A. (2002). O método fenomenológico na pesquisa. São Paulo: Cengage Learning.

Pavan, F. J., Meneghel, S. N.; \& Junges, J. R. (2008). Mulheres idosas enfrentando a institucionalização. Cadernos de Saúde Pública, 24(9), 2187-2189. <https://doi. org/10.1590/S0102-311X2008000900025>
Piexak, D. R., Freitas, P. H., Backes, D. S., Moreschi, C., Ferreira, C. L. L., \& Souza, M. H. T. (2012). Percepção de profissionais de saúde em relação ao cuidado a pessoas idosas institucionalizadas. Revista Brasileira de Geriatria e Gerontologia, 15(2), 201-208. <https://doi. org/10.1590/S1809-98232012000200003>

Rée, J. (2000). Heidegger: história e verdade em Ser e Tempo. São Paulo: Unesp.

Sá, R. N., \& Barreto, C. L. B. T. (2011). A noção fenomenológica de existência e as práticas psicológicas clínicas. Estudos de Psicologia (Campinas), 28(3), 389-394. <https://doi.org/10.1590/S0103-166X2011000300011>

Silva, M. R.; Santos, N. P. V.; Santos, R. A.; Cunha, G. R.; Torres, L. M. (2016). A percepção do idoso institucionalizado sobre os benefícios das oficinas terapêuticas. Revista Brasileira em Promoção da Saúde, 29 (Supl), 76-84. $\quad<$ http://dx.doi.org/10.5020/18061230.2016. sup.p76>

Teixeira, I. N. D. O.; Neri, A. L. (2008). Envelhecimento bem-sucedido: uma meta no curso da vida. Revista Psicol. USP, 19(1), 81-94. <http://dx.doi.org/10.1590/S0103$65642008000100010>$

Diogo Arnaldo Corrêa é Psicólogo, Doutor e Mestre em Psicologia Clínica pela Pontifícia Universidade Católica de São Paulo, Especialista em Análise Existencial e Logoterapia Clínica pela SOBRAL - Associação Brasileira de Logoterapia e Análise Existencial Frankliana. Formado em Filosofia pelo Instituto de Filosofia Santa Teresinha de São José dos Campos-SP (ITEFIST). Docente no Curso de Psicologia da Universidade de Mogi das Cruzes, em Mogi das Cruzes, SP (UMC). Endereço Institucional: Universidade de Mogi das Cruzes (UMC), Mogi das Cruzes, São Paulo, Brasil. Av. Dr. Cândido Xavier de Almeida e Souza, 200. Mogi das Cruzes, SP, CEP: 08780-911. Email: diogocorrea@umc.br

Carla de Santana Oliveira é Graduada em Psicologia pela Universidade de Mogi das Cruzes-SP. Foi pesquisadora bolsista do PIBIC na IES com projeto finalizado que abrangeu os temas envelhecimento, institucionalização, liberdade ontológica e fenomenologia. Email: olv.san.carla@gmail.com

Marlise Aparecida Bassani tem Graduação e Licenciatura em Psicologia, Mestrado e Doutorado em Educação pela Pontifícia Universidade Católica de São Paulo. É Professora Titular da Pontifícia Universidade Católica de São Paulo. Atualmente é Coordenadora do Núcleo Configurações Contemporâneas da Clínica Psicológica do Programa de Estudos Pós-Graduados em Psicologia Clínica da Pontifícia Universidade Católica de São Paulo. Email: marlise@pucsp.br

Recebido em 23.04.2017

Primeira Decisão Editorial em 20.06.2017 Segunda Decisão Editorial em 27.10.2017

Aceito em 26.11.2017 